\title{
High Efficiency Nuclear Power Plants Using Liquid Fluoride Thorium Reactor Technology
}

\author{
Albert J. Juhasz ${ }^{1}$ \\ NASA Glenn Research Center, Cleveland, Ohio 44135 \\ Richard A. Rarick ${ }^{2}$ and Rajmohan Rangarajan ${ }^{3}$ \\ Cleveland State University, Cleveland, Ohio 44115
}

\begin{abstract}
An overall system analysis approach is used to propose potential conceptual designs of advanced terrestrial nuclear power plants based on Oak Ridge National Laboratory (ORNL) Molten Salt Reactor (MSR) experience and utilizing Closed Cycle Gas Turbine (CCGT) thermal-to-electric energy conversion technology. In particular conceptual designs for an advanced $1 \mathrm{GWe}$ power plant with turbine reheat and compressor intercooling at a $950 \mathrm{~K}$ turbine inlet temperature (TIT), as well as near term 100 MWe demonstration plants with TITs of $950 \mathrm{~K}$ and $1200 \mathrm{~K}$ are presented. Power plant performance data were obtained for TITs ranging from 650 to $1300 \mathrm{~K}$ by use of a Closed Brayton Cycle (CBC) systems code which considered the interaction between major sub-systems, including the Liquid Fluoride Thorium Reactor (LFTR), heat source and heat sink heat exchangers, turbo-generator machinery, and an electric power generation and transmission system. Optional off-shore submarine installation of the power plant is a major consideration.
\end{abstract}

\section{Introduction}

T meeting the increasing demand for electrical energy today's global economies are faced with the dual problem I of declining fossil fuel resources (Hubbert 1956) and climate change due to atmospheric accumulation of "greenhouse gases," principally $\mathrm{CO}_{2}$ and methane. An obvious solution to both issues would be a power generation process that does not require fossil fuels and also does not have any gas emissions. Among the proposed near term "alternative energy" sources, the reliability and capacity factor of traditional nuclear fission power plants has steadily improved over the years to a level of $\sim 92$ percent, which is more than twice that of "solar" or "wind". Additional benefits from nuclear power are possible, if investment in "nontraditional" nuclear power generation is undertaken. The inherent advantages of such advanced power generation schemes were recognized by the United States Congress when it passed the "Energy Policy Act of 2005" (U.S. 109 $9^{\text {th }}$ Congress, 2005). Development of advanced nuclear power plants was advocated under "Title VI-Nuclear Matters" and the goals of the "Generation IV Nuclear Energy Systems Initiative" were spelled out under Subtitle C "Next Generation Nuclear Plant Project" (NGNPP). In essence, these goals were to generate electric power for base load energy demands and to produce hydrogen as a new carbon free fuel for vehicular transportation. Furthermore, Generation IV (Gen IV) power plants were to be highly economical, equipped with safety enhancements, have minimal waste, and be proliferation resistant. To meet these objectives a number of "closed cycle gas turbine" (CCGT) energy conversion systems either directly coupled to high temperature gas (cooled) reactors (HTGR), (Richards et al., 2005), or indirectly coupled via intermediate heat exchangers (IHX) to liquid cooled reactors have been proposed. For both configurations the gas turbine working fluid is helium (He), with power plant output ranging from tens of megawatts (MW) to gigawatt (GW) levels.

\footnotetext{
${ }^{1}$ Senior Research Engineer, Adjunct Professor, 21000 Brookpark Road, AIAA Associate Fellow.

${ }^{2} \mathrm{Ph}$.D Student, Department of Electrical Engineering, Nonmember.

${ }^{3} \mathrm{Ph} . \mathrm{D}$ Student, Department of Electrical Engineering, Nonmember.
} 


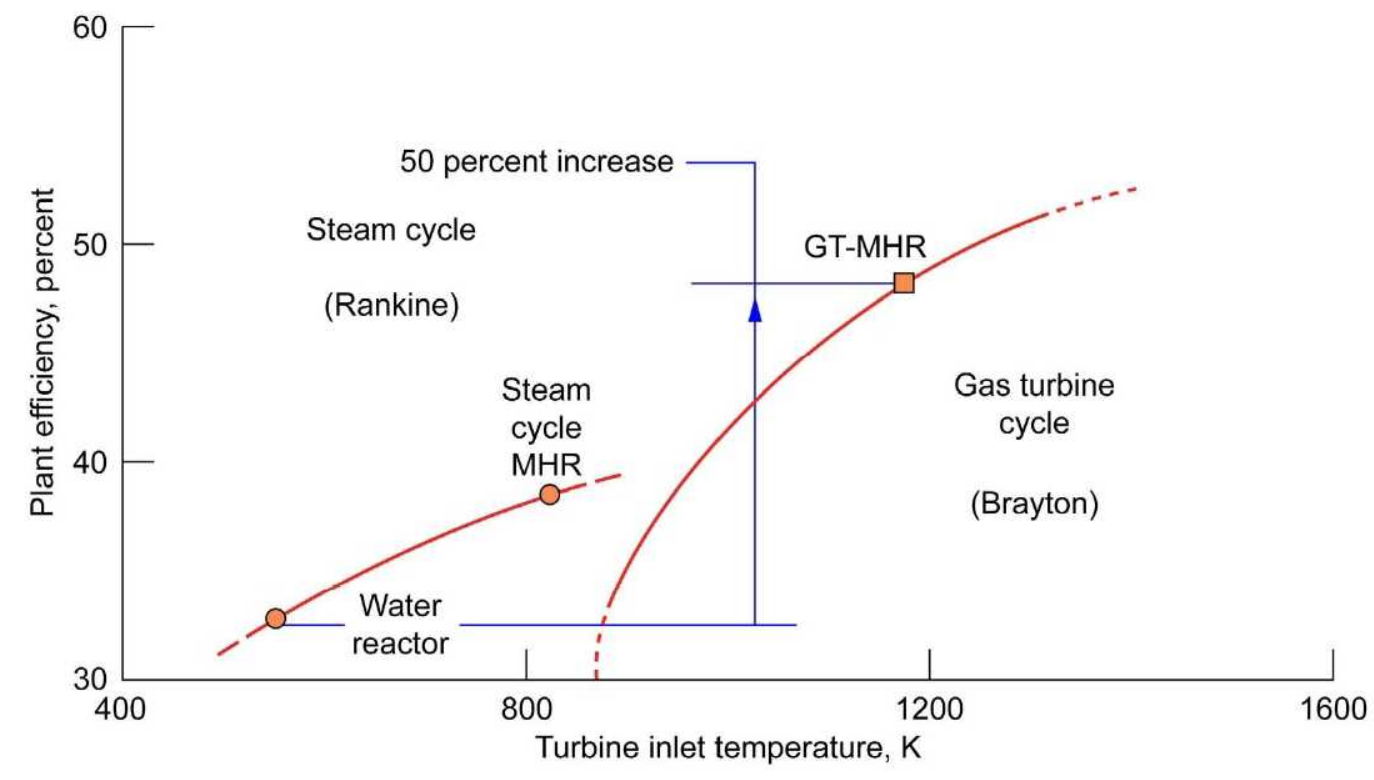

Figure 1: Energy Conversion Cycle Comparisons

A good comparison of the performance of power plants using either gas turbine (Brayton), or steam turbine (Rankine) energy conversion systems, in terms of the thermodynamic plant efficiency is shown in Fig. 1, which was adapted from the literature (LaBar 2002), except for the abscissa coordinates altered from " $F$ " to " $\mathrm{K}$ ". Due to the higher cycle temperature ratios enabled by the higher turbine inlet temperatures for gas turbine systems, a 50 percent increase in CCGT plant efficiency can be realized, when compared to the highest efficiency achievable with the steam cycle. Hence most Gen IV energy conversion systems are based on the CCGT power cycle, also referred to as the Closed Brayton Cycle (CBC). For optimum rotor-dynamic performance vertical orientation of the compressor- turbo-alternator machinery has been proposed (Zhao and Peterson 2005, Kodochigov 2008). Acronyms like High Temperature Gas Reactor (HTGR) or Gas Turbine Modular Helium Reactor (GT-MHR) (Baxi, 2006, 2009) refer to the directly CBC systems, while CBC energy conversion via the Very High Temperature Reactor (VHTR), MSR(Molten Salt Reactor), or LFTR (Liquid Fluoride Thorium Reactor) refer to indirectly heated cycles. Note that, due to the much higher heat transfer capability of liquid (molten) salt or metal, a VHTR can operate at higher outlet temperatures than the HTGR. The drawback is that additional investment in liquid-to-gas heat exchangers and circulating pumps must be made. However, such investment may be warranted if one considers that for a 1000 MWe plant generating power at $5 \mathrm{c} / \mathrm{KW}-\mathrm{hr}(\$ 50 / \mathrm{MW}-\mathrm{hr})$ each percent increase in plant efficiency translates into nearly $\$ 4.5 \mathrm{M}$ in additional revenue.

Hence the objective of this paper is to examine how gas turbine power systems could use fission reactor heat sources based on the LFTR technology, developed at ORNL (Engel, 1980) during the "Molten Salt Reactor Experiment" (MSRE) program.

\section{The Thorium Fuel Cycle and LFTR Power Plant}

The Thorium fuel cycle is based on a series of neutron absorption and beta decay processes initiated by neutron absorption and beta decay reactions starting with naturally occurring thorium-232 as the fertile material and the artificial uranium-233 $\left({ }_{92} \mathrm{U}^{233}\right)$ isotope as the fissile reactor fuel. Table 1 shows the three essential nuclear reactions (Glasstone and Sesonske, 1967): 
Table 1: Thorium - Uranium Breeding Cycle

$$
\begin{aligned}
& \text { 1. }{ }_{90} \mathrm{Th}^{232}+{ }_{0} \mathrm{n}^{1} \rightarrow{ }_{90} \mathrm{Th}^{233}+\gamma \quad \text { (neutron absorption) } \\
& \text { 2. }{ }_{90} \mathrm{Th}^{233} \rightarrow{ }_{-1} \beta^{0}+{ }_{91} \mathrm{~Pa}^{233} \text { (beta decay }-\lambda=22.3 \mathrm{~min} \text { ) } \\
& \text { 3. }{ }_{91} \mathrm{~Pa}^{233} \rightarrow{ }_{-1} \beta^{0}+{ }_{92} \mathrm{U}^{233} \text { (beta decay }-\lambda=27 \text { days) }
\end{aligned}
$$

The nuclear reaction indicated by "step 1" shows, that a neutron absorbed by thorium- 232 will bring about a transmutation to a new isotope, namely thorium-233 and emission of a gamma photon. Note that a logical source for the neutron required for absorption is a power producing fission reactor with the fertile thorium- 232 contained in an annulus or blanket enveloping the reactor core. The thorium-233 isotope next (step 2) emits an electron (beta decay) as it rapidly transmutes to protactinium-233. With a half life of only 22.3 minutes over 99.9 percent of the ${ }_{90} \mathrm{Th}^{233}$ is converted into ${ }_{91} \mathrm{~Pa}^{233}$ in 4 hours. In step 3 the protactinium-233 isotope itself undergoes a slow transmutation process by beta decay, with a half life of 27 days, there is a storage requirement or about 10 months for the protactinium-233 to decay to the fissile uranium-233.

\section{A. Molten Salt Reactor Technology}

The originators of this 'fluid fuel reactor' technology were nuclear researches at ORNL, under the direction of Alvin Weinberg who served as director of ORNL from 1955 to 1973. The motivation for and the intended first application was in support of the Nuclear Aircraft project in the late 1940s under the 'Homogeneous Reactor Experiment" (HRE) and the "Aircraft Nuclear Propulsion (ANP) project. Reactor outlet temperatures near $1100 \mathrm{~K}$ $\left(820^{\circ} \mathrm{C}\right)$ were achieved before the program was discontinued in 1961 . However the technology acquired was shifted to a ground based civilian version of a "meltdown proof" reactor, serving as heat source for both a steam power plant and later for a CBC (Engel et al., 1980).

A schematic diagram of the ORNL-MSR Gas turbine power plant is displayed in Fig. 2. Shown on the left side of the figure is a graphite matrix moderated MSR reactor with fuel salt mixture $\left(\mathrm{ThF}_{4}-\mathrm{U}_{233} \mathrm{~F}_{4}\right)$ being circulated by a pump through the core and to a primary (shell-tube) heat exchanger. Note that a parallel loop permits part of the fuel salt to be diverted to a processing plant and reintroduced into the core as 'purified salt'. - As one of the unique safety features, a melt-plug at the reactor bottom would permit the reactor fluid fuel to be drained into subcritical dump tanks, located in a underground storage facility, should the fuel salt temperature exceed a preset limit. A second pump circulates the liquid heat transfer fluid $\left(\mathrm{LiF}-\mathrm{BeF}_{2}\right)$ through an intermediary heat exchanger where the helium working fluid is heated to turbine inlet temperature. The high pressure-high temperature $\mathrm{He}$ is shown to flow through two parallel turbines which drive two intercooled series compressors and the electric power generator, all mounted on the same shaft. The turbine exhaust flows pass through the hot side of a recuperator where thermal energy is transferred to the high pressure compressor discharge flow before entering the water cooled heat sink heat exchanger (HSHX) which lowers the working fluid temperature to the value required by the LPC (low pressure compressor) inlet condition. The compressor raises both pressure and temperature of the He working fluid before the fluid is cooled back to near inlet temperature by the intercooling He-water heat exchanger. Due to the lower temperature at the inlet of the HPC (high pressure compressor), the compressor work will be reduced significantly, thus allowing more shaft power for the generator and thereby leading to higher plant efficiency. As a final step in completing the circuit, the He working fluid exiting the high pressure compressor enters the cold side of the recuperator where it is preheated by the turbine exhaust stream. The helium then enters the secondary heat exchanger where it is heated to the turbine inlet temperature requirement as explained above. 
Although not shown in the schematic, reactor core heat can also be used for $\mathrm{H}_{2}$ production by processes like high temperature electrolysis of water, or the water gas shift reaction. Thus all of the objectives set forth under the Energy Policy Act of 2005 could be accomplished with advanced nuclear technology as represented by MSR or LFTR.

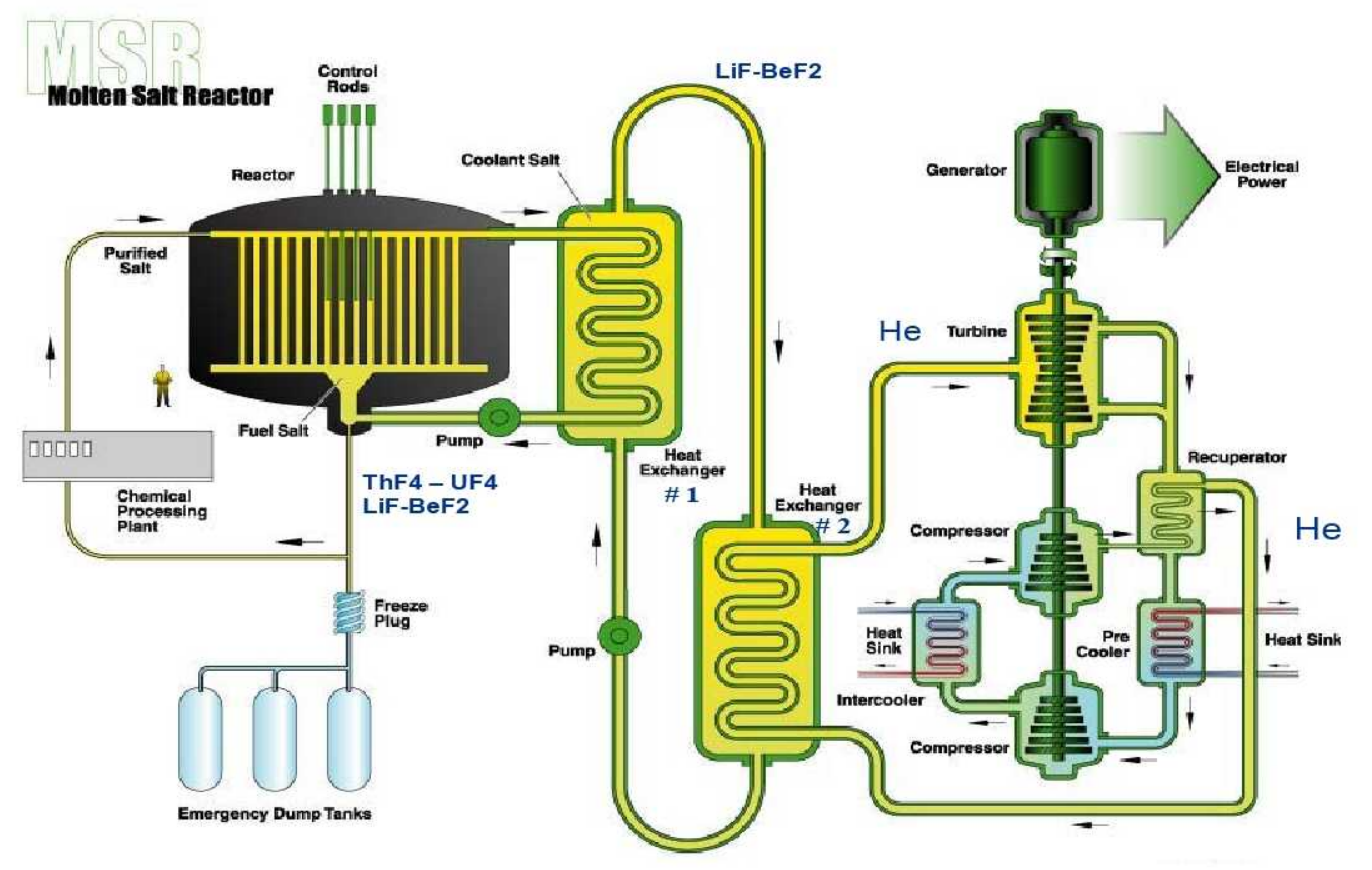

Figure 2: ORNL's MSR/LFTR Power Plant with CBC Conversion

\section{B. Technological Advantages of LFTR Power Plants}

Compared to traditional nuclear reactors which "burn" the fissile uranium isotope $\mathrm{U}_{235}$ the LFTR uses fissile $\mathrm{U}_{233}$ which is derived from $\mathrm{Th}_{232}$. But whereas $\mathrm{U}_{235}$ constitutes only 0.7 percent of mined natural uranium, practically all of the Thorium can be converted to $\mathrm{U}_{233}$, and no processing for enrichment is needed. As will be shown in a later section of this paper, at turbine inlet temperatures of $1200 \mathrm{~K}$ closed cycle gas turbine thermal energy conversion efficiency, $\eta_{t}$, of over 50 percent can be attained, as compared to a 30 to 35 percent efficiency for currently operating steam turbines plants with inlet temperatures of approximately $570 \mathrm{~K}\left(300^{\circ} \mathrm{C}\right)$. Thus a factor of three hundred times as much output electric power per unit mass of raw fuel ore (uranium oxide $\left(\mathrm{U}_{3} \mathrm{O}_{8}\right)$ versus Thoria $\left(\mathrm{ThO}_{2}\right)$ can be obtained via the Thorium fuel cycle with closed cycle gas turbine energy conversion. As a result fission fragment waste products are reduced by a commensurate amount, and their radioactivity would decay to background levels in less than 300 years, as contrasted to over 10,000 years for currently used reactors, thus obviating the need for long term storage, such as at Yucca Mountain. The thermal spectrum LFTR concept is inherently safe, with a negative temperature coefficient of reactivity, thus making a "core meltdown" due to loss of coolant impossible. Since the fuel is a pumped liquid solution of $\mathrm{LiF}-\mathrm{BeF}_{2}-\mathrm{UF}_{4}$, refueling can be accomplished without reactor shutdown. The fissile fuel can also be made "proliferation resistant" by permitting it to be contaminated (denatured) with small amounts of $U_{232}$ to increase its dose rate which would greatly reduce its unshielded exposure time and greatly increase detectability.

With Thorium ores, such as Monazite, being four times more abundant in the earth's crust than uranium ores, over 60 percent of the worlds resources are located in the following democratically governed countries: Australia 
(18 percent), United States (16 percent), India (13 percent), Brazil (9 percent), and Norway (5 percent). Thus future global energy demands could be met by these Thorium sources for over several tens of millennia.

\section{Conceptual Design Modeling of Gas Turbine LFTR Nuclear Power Plants}

Having established that Closed Cycle Gas turbine power plants with both directly or indirectly supplied thermal energy from nuclear heat sources would best meet the NGNPP-Gen IV power plant requirements, an author generated CBC code previously used in the modeling of space and planetary surface power systems (Juhasz 2005, 2006,2007 ) was modified to meet the modeling requirements of terrestrial nuclear power plants. Special emphasis was placed on incorporating the two series heat exchanger requirements of LFTR-reactors as exemplified by ORNL MSRE technology.

Furthermore the provision for treating $\mathrm{CBC}$ compression and turbine expansion processes as composed of separate incremental series steps allowed for realistic modeling of power systems with compressor intercooling and/or turbine reheat options. Since cycle reject heat and intercooling heat transfer is accomplished via gas-water heat exchangers, the space radiator heat rejection sub-routines were bypassed in the modeling computations. Allowing for the working fluid passing through heat exchangers on the cycle hot side, recuperator, compressor intercooler and heat sink, the cycle pressure drop was set at 4 percent. Thus the turbine overall turbine pressure ratio for up to three series machines was 96 percent of the overall pressure ratio produced by the compressors. Provision was added to compute and display local pressure and temperature state points along the system schematic diagrams for moiling simulations for different cycle configurations, TITs and power output levels.

A list of key input values which were kept constant is shown in table 2.

Table 2: Key Cycle Input Parameters

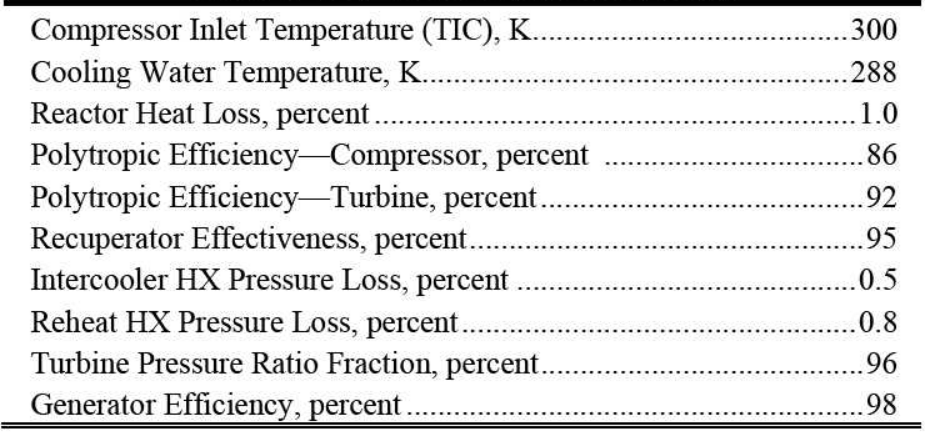

Several conceptual power plant cycle configurations were modeled using the code briefly described above. As shown in Fig. 3, the first of these is for a 1000 MWe power plant with turbine reheat and compressor intercooling (availability of water cooling reservoirs assumed), with a TIT of $950 \mathrm{~K}$. With three series turbines and compressors, and the required heat exchangers on the hot side and cold side of the cycle, a fairly convoluted cycle schematic was analyzed. Note that the total $\mathrm{He}$ mass flowrate was only about $681 \mathrm{~kg} / \mathrm{s}$ for this three series turbomachine configuration with an overall pressure ratio of 8 , with each stage ratio of 2 . The specific work parameter of $1468 \mathrm{~kJ} / \mathrm{kg}$ expresses the ratio of total power output of $1000 \mathrm{MWe}=10^{6} \mathrm{~kJ} / \mathrm{s}$ to $680 \mathrm{~kg} / \mathrm{s}$. This flowrate is only a third of the over $2100 \mathrm{~kg} / \mathrm{s}$ that would have been required for accomplishing the same power output with one large single compressor and turbine and the resulting specific work for this case would be less than $500 \mathrm{~kJ} / \mathrm{kg}$. So the system complexity is offset somewhat by much smaller rotating machinery and heat exchanger size. However another drawback is that, due to the cascading pressure levels the turbo-generator speeds (in rpm) optimize at 7200 for the HPT, 5400 for the MPT and 3600 for the LPT. This would require speed reducer transmissions for changing the intermediate and high pressure turboset speeds to $3600 \mathrm{rpm}$, for generation of $60 \mathrm{~Hz}$ electric power via 2 pole alternators. 


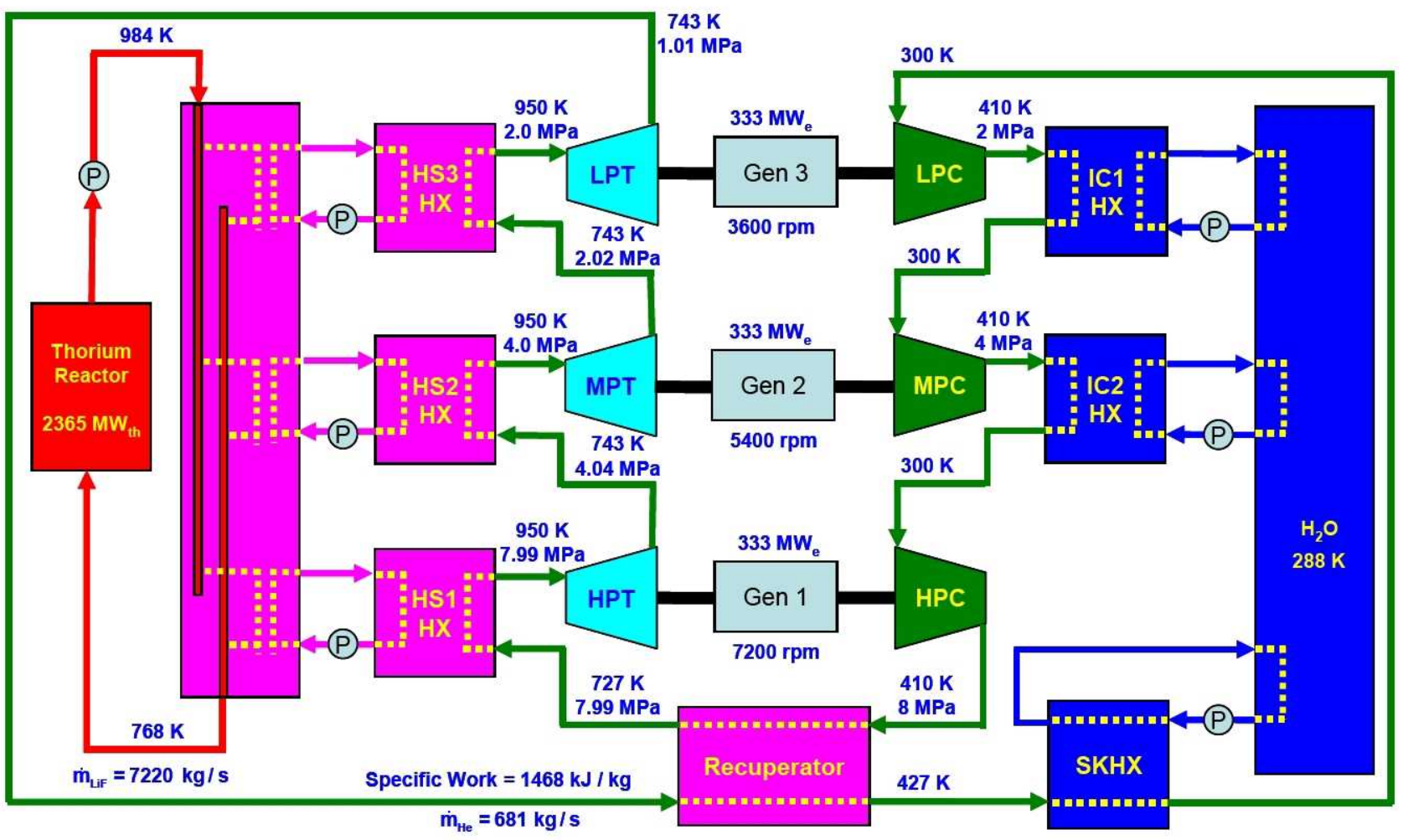

Figure 3: Schematic of 1 GW Liquid Fluoride Thorium Reactor Power Plant with 950 K Turbine Reheat and Compressor Intercooling. Plant Efficiency is $\sim 42$ percent.

The reactor thermal power is shown to be $2365 \mathrm{MWt}$, which indicates a pant thermal efficiency of 42.3 percent. Even after subtracting the approximately $3 \mathrm{MWe}$ for combined pump power requirements the plant efficiency is still above 42 percent for the $950 \mathrm{~K}$ TIT, requiring a reactor outlet temperature of under $990 \mathrm{~K}$, assuming high effectiveness heat exchangers. Of course, just like for the ORNL MSR system, the primary reactor fuel-coolant is uranium tetra fluoride $\left(\mathrm{U}_{233} \mathrm{~F}_{4}\right)$ which may also contain $\mathrm{LiF}-\mathrm{BeF}_{2}$ eutectic in solution. The secondary heat exchanger fluid is $\mathrm{LiF}-\mathrm{BeF}_{2}$ liquid salt with a melting point of $\sim 630 \mathrm{~K}$.

The next cycle analyzed, shown in Fig. 4, has been greatly simplified by removing the reheat feature, but keeping the three series intercooled compressors. The TIT is still $950 \mathrm{~K}$, but the output power level is reduced to 100 MWe. Note that the overall pressure ratio for this system is $\sim 2.21$ (i.e., $2.08 \mathrm{MPa}: 0.94 \mathrm{MPa}$ ). Even though there is no 'reheat', the total turbine expansion work is split into two sections. The HPT (high pressure turbine) work is dedicated to driving the three series compressors with intercooling after the first and the second stage. The output of the low pressure turbine (LPT) at a TIT $-834 \mathrm{~K}$ is used to drive the $100 \mathrm{MWe}$ generator. Although the turbine speed still optimized at $7200 \mathrm{rpm}$, higher power output levels with higher machine diameters would lead to optimum turbine speeds near $3600 \mathrm{rpm}$. But to design a $3600 \mathrm{rpm}$ turbo-generator for a $100 \mathrm{MWe}$ output the operating pressure levels could be reduced, albeit the turbomachine diameters would thereby need increase. 


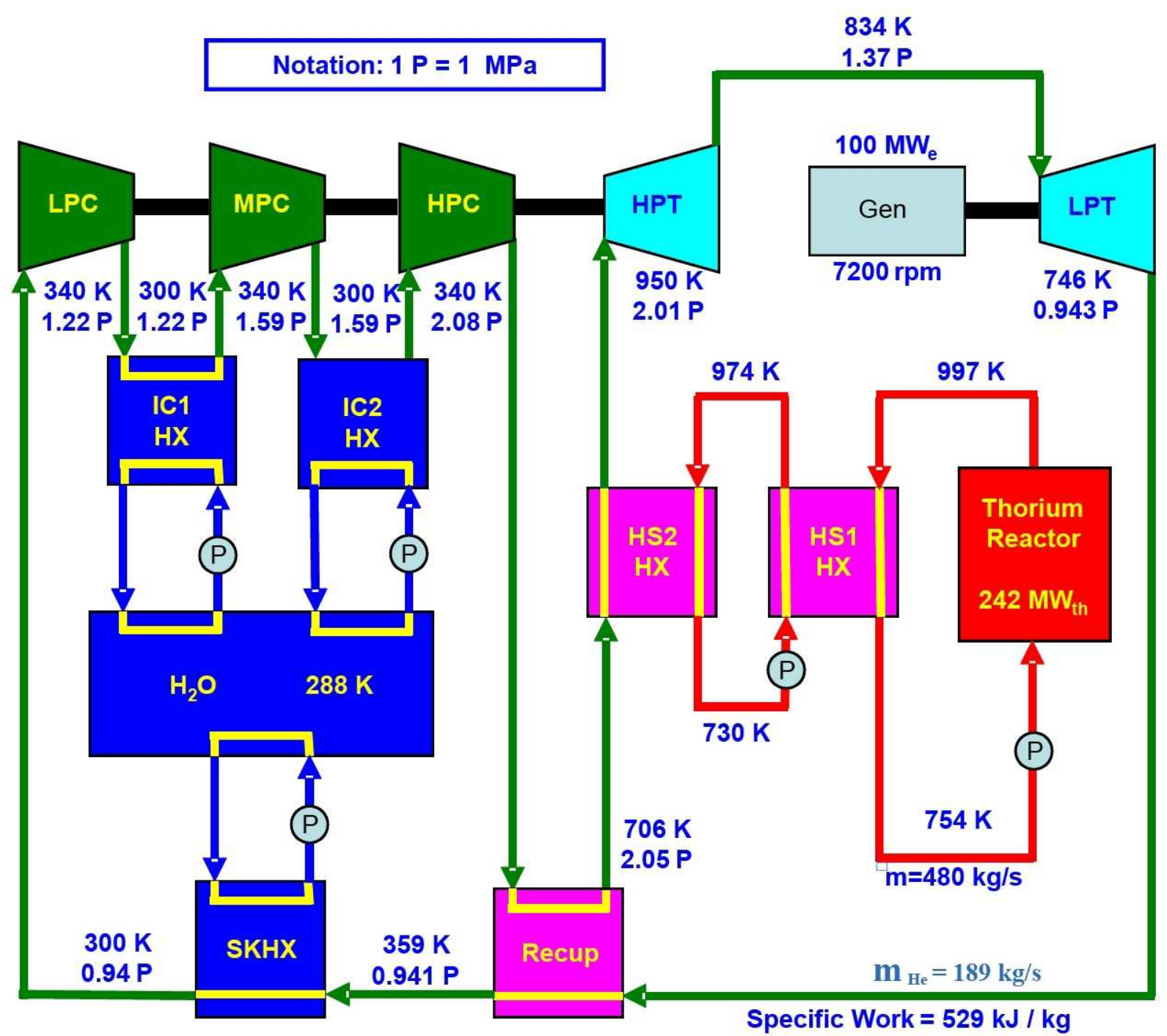

Figure 4: Schematic of 100 MWe Liquid Fluoride Thorium Reactor Power Plant with 950 K Turbine (No Reheat) and Compressor Intercooling. Plant Efficiency is $\sim 41.3$ percent.

Note, that even without reheat the plant thermal efficiency only dropped about one percent. Compared to Fig. 3, the number of hot side heat exchangers has been reduced from four to two. Such beneficial results with intercooling only were also pointed out in the reference literature (Frutschi, 2005). Note that the 'specific work' parameter has decreased to about $530 \mathrm{~kJ} / \mathrm{kg}$. This is indicated by the relatively high He mass flowrate requirement of $189 \mathrm{~kg} / \mathrm{s}$ for this $100 \mathrm{MWe}$ power output, when compared to the $681 \mathrm{~kg} / \mathrm{s}$ mass flow for the $1000 \mathrm{MWe}$ case of Fig. 3. The primary and intermediate heat exchanger mass flows were computed on the basis of thermal capacity and density of the respective 'liquid fuel' $\left(\mathrm{U}_{233} \mathrm{~F}_{4}\right)$ and $\mathrm{LiF}-\mathrm{BeF}_{2}$ heat transfer fluids. 


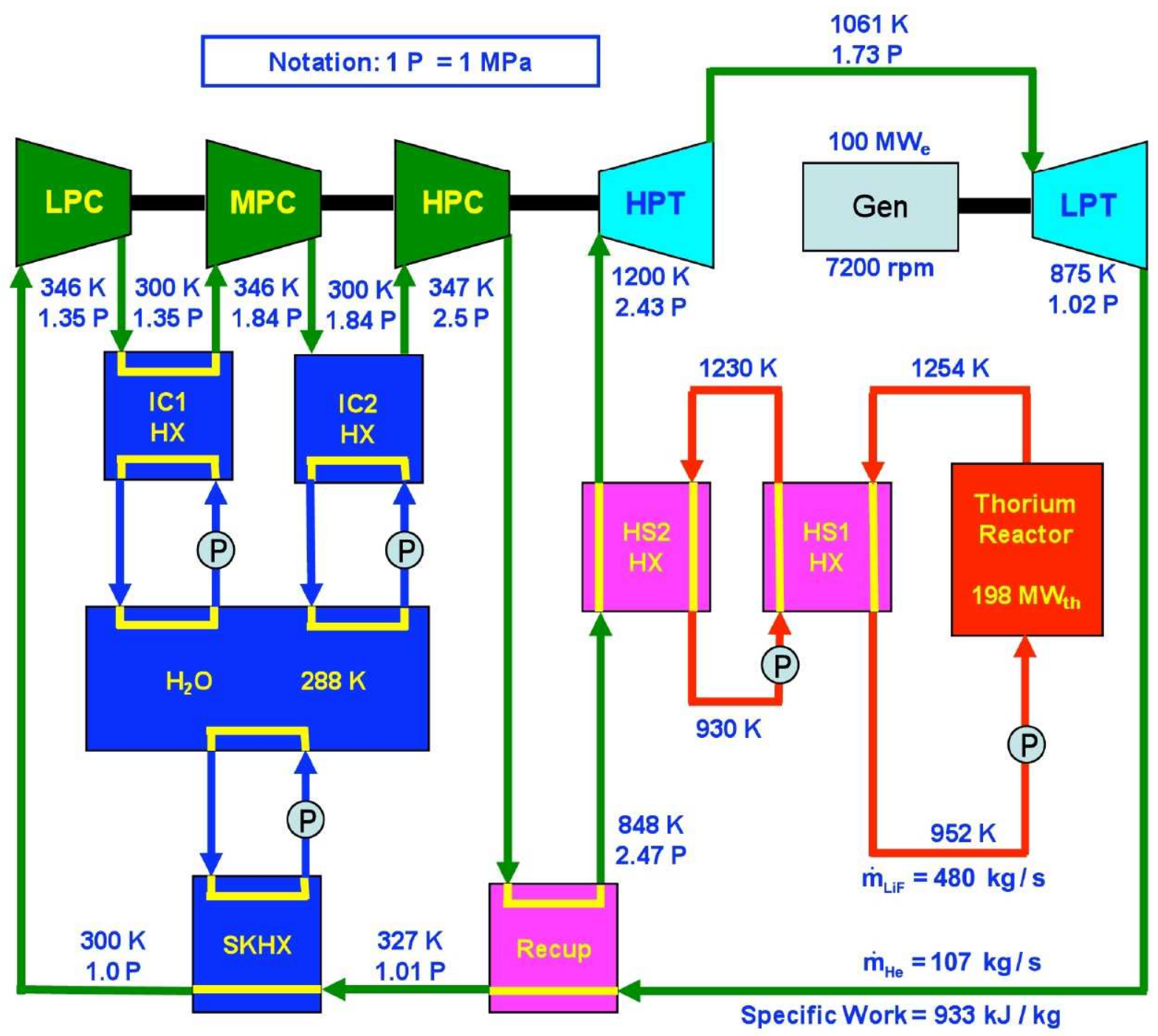

Figure 5: Schematic of 100 MWe Liquid Fluoride Thorium Reactor Power Plant with $1200 \mathrm{~K}$ Turbine (No Reheat) and Compressor Intercooling. Plant Efficiency is $\sim 50.5$ percent.

As shown in Fig. 5, the last case analyzed was for a 100 MWe power output with the 'intercool only' option. But the TIT was increased to $1200 \mathrm{~K}$, thus providing a cycle temperature ratio of 4 . For this higher temperature ratio the plant thermodynamic efficiency increased to 50.5 percent and the overall optimum pressure ratio to 2.5 . The specific work parameter almost doubled to $933 \mathrm{~kJ} / \mathrm{kg}$. This is as also reflected by the reduced $\mathrm{He}$ mass flowrate of $107 \mathrm{~kg} / \mathrm{s}$. Note also that the high pressure turbine exit temperature, which is also the inlet temperature for the low pressure turbine, increased from $834 \mathrm{~K}$ for the case discussed in Fig. 4 to $1061 \mathrm{~K}$ for this higher TIT.

The higher plant thermal efficiency and specific work values, coupled with lower working fluid mass flowrate requirement, reinforce the fact that higher peak cycle temperatures enabled by advances in high temperature materials technology are the key to achieving economies in lower heat input requirements and lower component sizes. These promising trends augur well for rewards in the future if required investments are made in the present.

The results of a systematic increase in TIT from $650 \mathrm{~K}$ to $1300 \mathrm{~K}$ for 'Intercooled Only' and 'Intercooled + Reheated' gas turbine systems are shown in Figs. 6 and 7, respectively. The first case, illustrated by the red curves, represents configuration of three series compressors and a single turbine. 


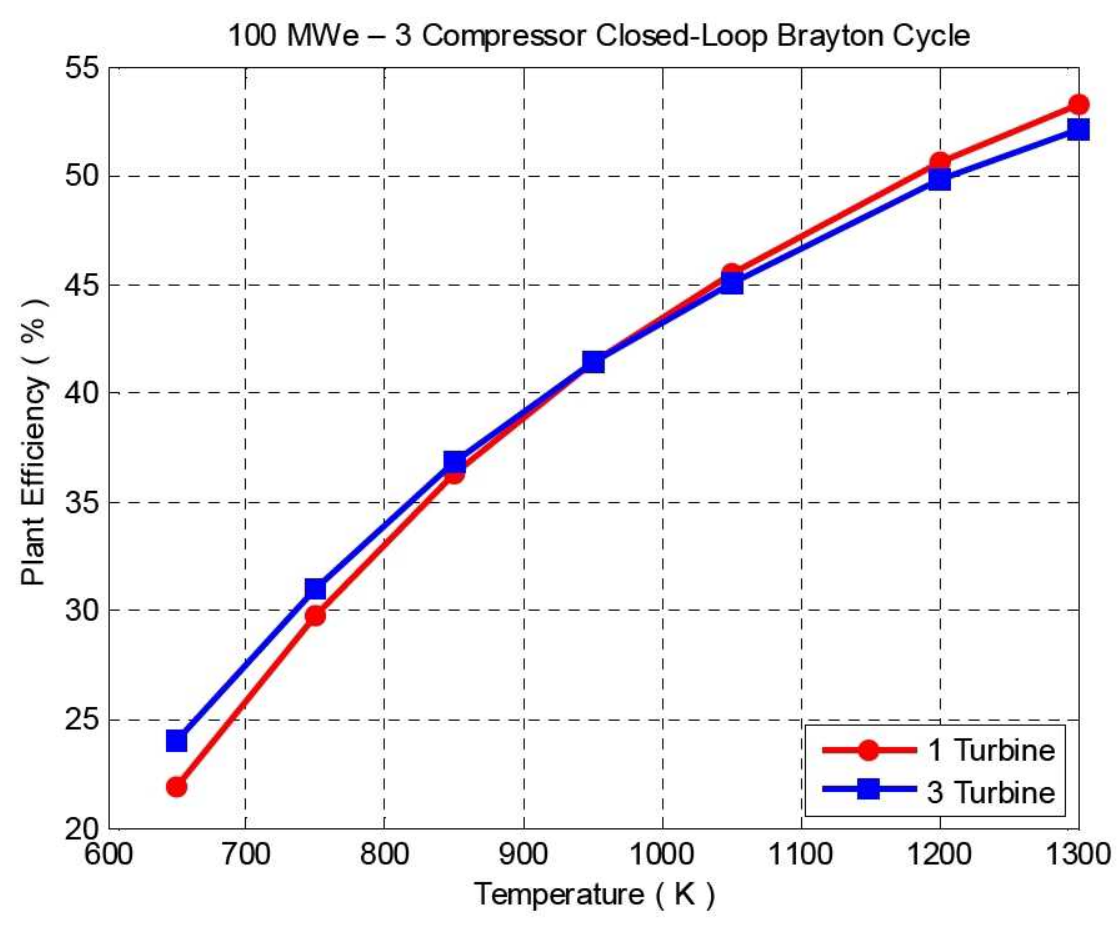

Figure 6: Power Plant Efficiency as a Function of Turbine Inlet Temperature for only Intercooled (1 Turbine) and Intercooled + Reheated (3 Turbines) - 100 MWe CCGT Power Plant.

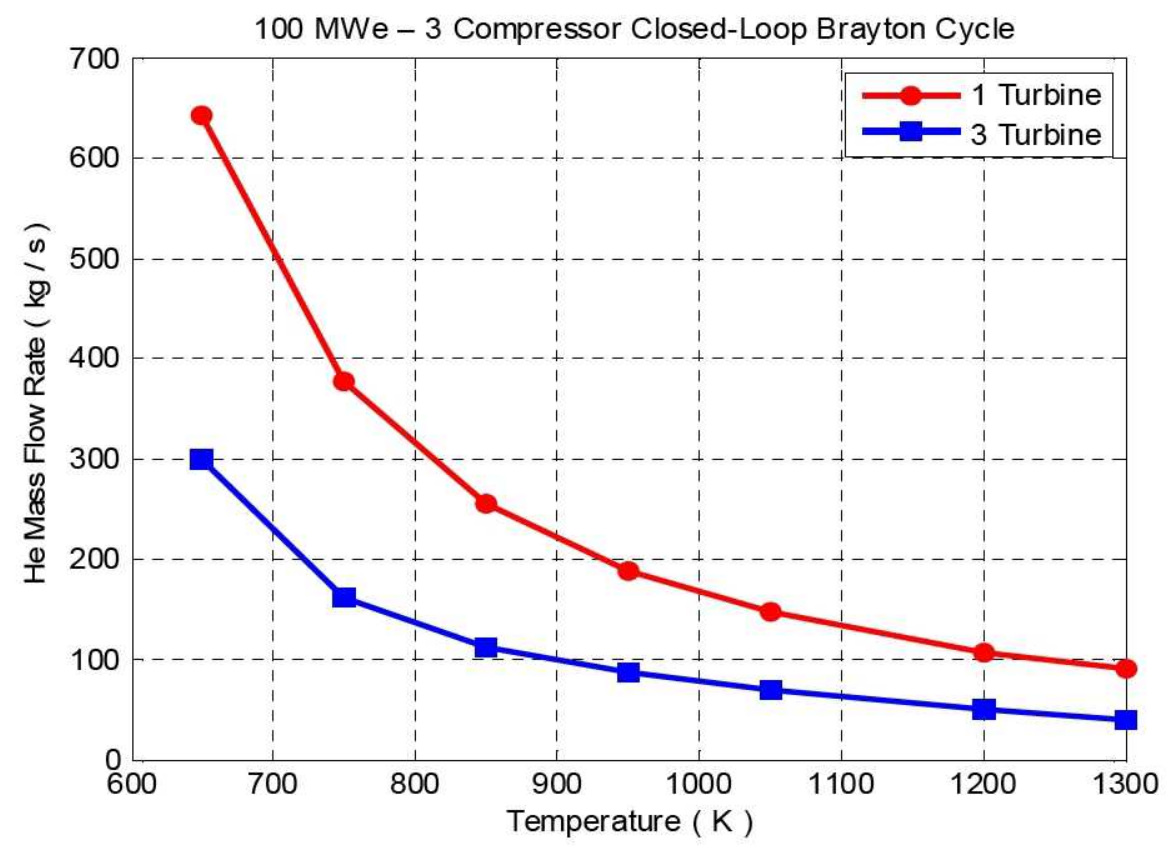

Figure 7: Power Plant Mass Flowrate as a Function of Turbine Inlet Temperature for only Intercooled (1 Turbine) and Intercooled + Reheated (3 Turbines)-100 MWe CCGT Power Plant. 
The second case, illustrated by the blue curves, is representative of the three reheated series turbines plus three series intercooled compressor case, as shown in Fig. 3. The dramatic increase in power plant thermal efficiency from the low 20 's percent range for a TIT of $650 \mathrm{~K}$, to over 53 percent at a TIT of $1300 \mathrm{~K}$ is shown in Fig. 6. For the change in turbine inlet temperature shown the optimum pressure ratios increase from about 1.8 to 2.5 for the 'Intercool only' case. But for the 'Intercool + Reheat' case the optimum pressure ratios increase from about 2.8 to near 8.0 over the same temperature range. Due to the higher pressure ratios, the isentropic compressor efficiencies are lower for the same polytropic value of 86 percent as shown in Table 2. This explains why the efficiency values for the 'Intercooled only' configuration surpass those for the 'Intercool + Reheat' at the high turbine inlet temperatures. But, regarding total helium mass flowrate, Fig. 7 shows that while the mass flow decreases by a factor of $\sim 6$ over the temperature range, the three turbine 'Intercool + Reheat' configuration requires less than half the mass flow of the 'Intercool only' option. Since turbo-machine and heat exchanger size at the same operating pressure is proportional to working fluid mass flow, having larger sized components is the cost for reduction in system complexity offered by the single turbine 'Intercool only' option.

\section{Plant Sub-Marine Basing and High Voltage DC Power}

Although proposed here only in conceptual form with detailed designs to be generated at some future time, an LFTR-CBC power plant could be based off shore in a large submarine pressure vessel and the three phase ac power generated could be transformed to high Voltage before rectification-conversion to HVDC and transmission via submarine cables to users in coastal regions. A preliminary electrical wiring scheme for power output from two parallel turbo-generators is shown in Fig. 8.

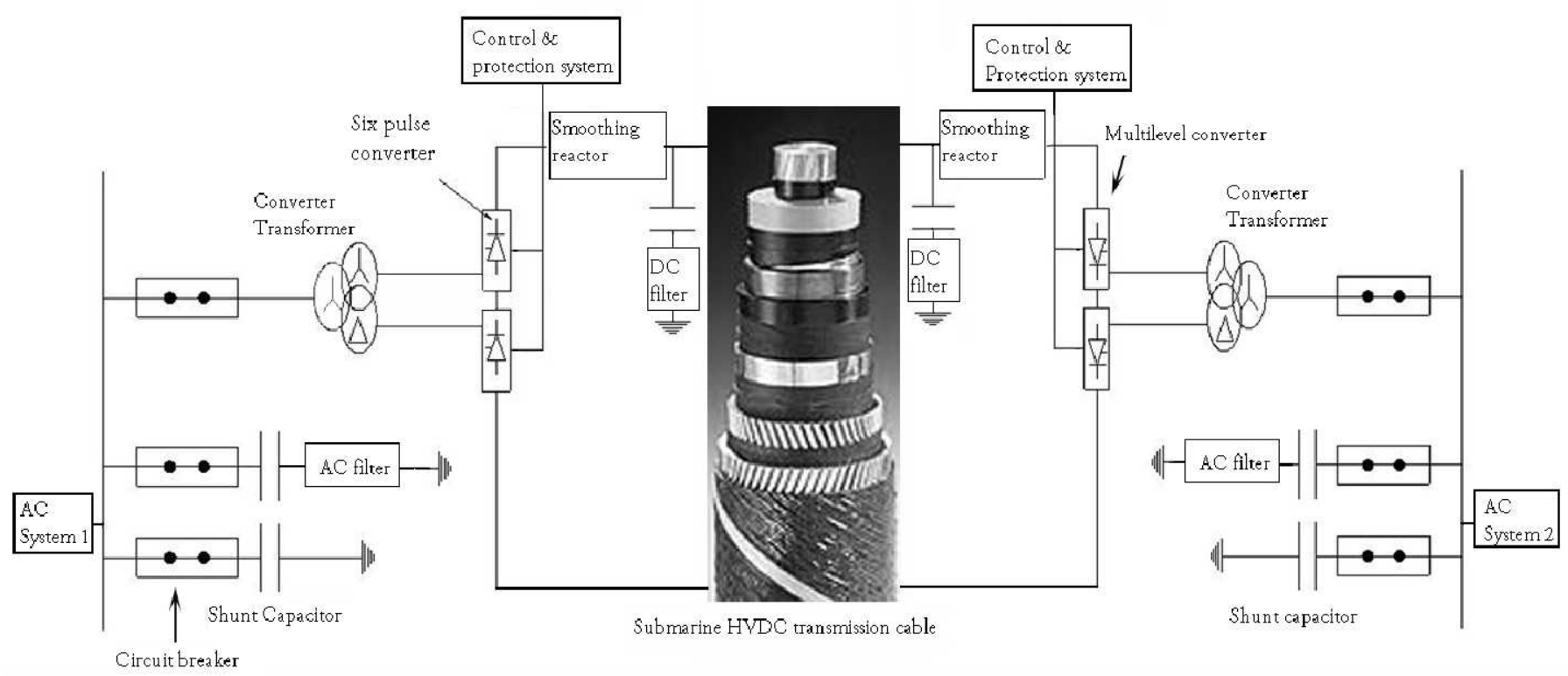

Figure 8: Possible Wiring for HVDC Power Transmission between Source and Load.

The generator employed for the conversion process is an ac synchronous generator. The generated ac voltage is converted into dc voltage using a rectifier. A converter transformer is employed to step up the generated voltage to the necessary transmission voltage level. The converter transformer has two secondary windings, a delta and a Ywinding. This construction facilitates a 12-pulse rectification in the rectifiers. The construction of the converter transformer also suppresses the fifth and the seventh harmonic in the system. The dc voltage output from the ac-dc rectifier has very low ripple and hence low losses. Smoothing reactors are employed to reduce ripples from the system in conjunction with DC The layout of a HVDC transmission system is shown in figure below. The mechanical energy filters. This improves the power quality of the transmitted power. The smoothing reactor, DC filter also act as protective devices and reduce the current surges in the system, in case of a fault. The smooth, 
filtered dc voltage is transmitted via submarine HVDC transmission cable. The transmitted dc has to be converted back to ac voltage for transmission and distribution purposes. The dc is converted into ac by employing a low loss, high efficiency multilevel converter. The inverted voltage is stepped up or down depending on the voltage on the terrestrial grid. The layout shows the other protective devices in the system. Some obvious advantages of a HVDC over HVAC transmission system are:

1. Economically cheaper - two cables only

2. Efficiency as the system losses are lower

3. Reliability - underground cable location

4. Security_-buried or under-ground cables are less prone to sabotage

The offshore basing of nuclear power plants would also make them more acceptable for location within a few miles of metropolitan centers.

\section{Concluding Remarks}

Conceptual designs for ground based gas turbine energy conversion power plants with advanced nuclear fission reactor heat input were analyzed using an author generated code with the capability to model gas turbine power systems with compressor intercooling and/or turbine reheat provisions. It was shown that, given high quality heat exchanger and turbomachine technology with $1200 \mathrm{~K}$ inlet temperature, power plants with a thermodynamic efficiency of 50 percent could be constructed.

In particular a nontraditional nuclear fuel, namely uranium-233, derived from natural thorium, nuclear power plants using a Liquid Fluoride Thorium Reactor (LFTR) would offer great benefits for ensuring future energy supplies, reduction of adverse climate effects due to greenhouse gas emissions, and invigoration of the world wide economy. With the inherently higher proliferation resistance of the Thorium fuel cycle LFTR's meet the requirements of the Gen IV nuclear power plants as spelled out in the Energy Policy Act of 2005.

As confirmed by an author generated $\mathrm{CBC}$ code, even without the complexity of turbine reheat cycles, using 'intercooled only' option, at least 50 percent of the thermal energy from (LFTRs) could be converted by gas turbine driven generators (operating at $\sim 1200 \mathrm{~K}$ turbine inlet temperature) for electric power production during peak demand periods. Both thermal and electrical energy would be available during "off peak" periods for hydrogen production by elevated temperature electrolysis of water or chemical processes such as the water gas shift reaction. This approach would both supply electric power by using environmentally clean nuclear heat which does not generate green house gases, and it would also provide a clean fuel for the future, when, due to increased global demand and the decline in discovering new deposits, our supply of liquid fossil fuels will have been used up within the next 30 to 50 years, as predicted by the Hubbert model and confirmed by other global energy consumption prognoses.

The thermal spectrum LFTR concept is inherently safe, with a negative temperature coefficient of reactivity, thus making a "core meltdown" due to loss of coolant impossible. Since the fuel is a pumped liquid solution of $\mathrm{LiF}^{-\mathrm{BeF}_{2}-}$ $\mathrm{UF}_{4}$ refueling can be accomplished without reactor shutdown. The fissile fuel can also be made "proliferation resistant" by permitting it to be contaminated (denatured) with small amounts of $U_{232}$ to increase its dose rate which would greatly reduce its unshielded exposure time and greatly increase detectability.

With Thorium ores, such as Monazite, being four times more abundant in the earth's crust than uranium ores, over 60 percent of the worlds resources are located in the following democratic countries: Australia (18 percent), United States (16 percent), India (13 percent), Brazil ( 9 percent), and Norway (5 percent). Thus future global energy demands could be met by these Thorium sources for over several tens of millennia.

\section{Acknowledgments}

This work was conducted at NASA Glenn Research Center's Thermal Energy Conversion Branch and Cleveland State University (CSU). Any opinions expressed are those of the authors and do not necessarily reflect the views of NASA, CSU, or the Department of Energy. 


\section{References}

Baxi, C.B. et al: "Evaluation of alternate power conversion designs for the GT-MHR," $3^{\text {rd }}$ International Topical Meeting on High Temperature Reactor Technology, Johannesburg, South Africa, Oct. 1-5, 2006. Published in Nuclear Engineering and Design, HTR-2006.

Baxi, C.B. et al: "Development of the GT-MHR Turbo Machine," Proceedings of the ASME Turbo Expo 2009, Jun. 8-12, 2009, Orlando, FL.

Briant, Raymond C., and Weinberg, Alvin M. (1957). "Molten Fluorides as Power Reactor Fuels" (PDF). Nuclear Science and Engineering; 2, 797-803. http://www.energyfromthorium.com/pdf/NSE_moltenFluorides.pdf. (Retrieved on 2008-05-18.)

Engel, J. R. et al: "Conceptual Design Characteristics of a Denatured Molten-Salt Reactor with Once-Through Fueling," ORNL/TM-7207, Jul. 1980.

Frutschi, H. U.: "Closed Cycle Gas Turbines-Operating Experience and Future Potential," $1^{\text {st }}$ ed. 2005; ASME, Three Park Avenue, New York, NY 10016.

Glasstone, S. and Sesonske, A.: "Nuclear Reactor Engineering" $3^{\text {rd }}$ ed., D. Van Nostrand, Princeton, NJ, 1967.

Hubbert, M. K.: "Nuclear Energy and the Fossil Fuels," Publication No. 95, Shell Development Co.-Exploration and Product Research Division, Houston, TX, Jun. 1956.

Juhasz, A. J.: "Analysis and Numerical Optimization of Gas Turbine Space Power Systems with Nuclear Fission Reactor Heat Sources" Doctoral Dissertation, Cleveland State University, May 25, 2005.

Juhasz, A. J.; and Sawicki, J. T.: "Lunar Surface Power Systems with Fission Reactor Heat Sources," NASA/TM-2005-214003, Nov. 2005.

Juhasz, A. J.: "Multi-Megawatt Gas Turbine Power Systems for Lunar Colonies," NASA/TM-2006-214658, Dec. 2006.

Juhasz, A. J. "Heat Transfer Analysis of a Closed Brayton Cycle Space Radiator," NASA/TM-2007-215003, Aug. 2007.

Kodochigov, N. G. et al "Development of the GT-MHR Vertical Turbomachine Design," $4^{\text {th }}$ International Topical Meeting on High Temperature Reactor Technology, September 2008, Washington, D.C., USA.

LaBar, Malcolm P.: "The Gas Turbine-Modular Helium Reactor: A Promising Option for Near Term Deployment," General Atomics Report GA-A23952, Apr. 2002.

Richards, Matthew B., et al. "The H2-MHR: Nuclear Hydrogen Production Using the Modular Helium Reactor," Paper 5355 of Proceedings of the ICAPP '05, Seoul, Korea, May 15-19, 2005.

U.S. 109 ${ }^{\text {th }}$ Congress PUBLIC LAW 109-58 "Energy Policy Act of 2005," Aug. 8, 2005.

Zhao, H. and Peterson, P.F.: "Optimization of Advanced High Temperature Brayton Cycles with Multiple Reheat Stages" $11^{\text {th }}$, International Topical Meeting on Nuclear Reactor Thermal-Hydraulics (NURET-11). Popes' Palace Conference Center, Avignon, France, Oct. 2-6, 2005 